\title{
Molecular Characterization of Uzbekistan Isolates of Fusarium oxysporum f. sp. vasinfectum
}

\author{
Sharof S. Egamberdiev ${ }^{1}$, Mauricio Ulloa ${ }^{2 \dagger}$, Sukumar Saha ${ }^{3 \dagger}$, Ilkhom B. Salakhutdinov ${ }^{1 \dagger}$, Alisher Abdullaev', Ludmila A. Glukhova ${ }^{1,4}$, \\ Azoda T. Adylova ${ }^{1}$, Brain E. Scheffler ${ }^{5}$, Johnie N. Jenkins ${ }^{3}$ and Ibrokhim Y. Abdurakhmonov ${ }^{1 *}$ \\ *Correspondence: genomics@uzsci.net \\ ${ }^{\dagger}$ These authors contributed equally to this work. \\ 'The Center of Genomics and Bioinformatics, Academy of Sciences of Uzbekistan, Ministry of Agriculture \& Water Resources of \\ Uzbekistan, and 'Uzpakhtasanoat' Association, University street-2, Kibray region, Tashkent 111215, Uzbekistan. \\ ${ }^{2}$ USDA-ARS, SPA, CSRL, Plant Stress and Germplasm Development Research, 3810 4th Street, Lubbock, TX 79415 USA. \\ ${ }^{3}$ USDA-ARS, Crop Science Research Laboratory, Genetics and Precision Agriculture, 812 Highway 12E, Mississippi State, MS 39762, \\ USA.
}

${ }^{4}$ Institute of Genetics and Plant Experimental Biology, Academy of Sciences of Uzbekistan. Yuqori Yuz, Qibray region Tashkent district, 111226 Uzbekistan.

${ }^{5}$ USDA-ARS, Genomics and Bioinformatics Research Unit, 141 Experiment Station Road, Stoneville, MS 38776, USA.

\begin{abstract}
A collection of isolates of Fusarium oxysporum f. sp. vasinfectum (FOV) from cotton in Uzbekistan was characterized based on candidate gene sequencing approach. As a first step, cotton seedlings were artificially re-infected with randomly selected 8 unknown FOV isolates from the collection, FOV strains were re-isolated, and monospore cultures were obtained for genomic DNA preparation. Candidate genes such as elongation factor (EF-1 $\alpha$ ), beta-tubulin (BT), and ribosomal DNA (rDNA) were sequenced from the genomic DNAs of these unknown Uzbekistan FOV isolates and a set of 13 known races of FOV (races 1, 2, 3, 4, 6, 7, 8, and Australian VCG1112), collected from world research centers. A parsimony based phylogenetic analysis of known races of FOV together with unknown FOV isolates from the Uzbekistan collection clearly suggested that Uzbekistan FOV genotypes can be classified as race 1, $2 \& 6$, race 3, and race 4 or 7 . Based on EF-1 $\alpha$ pair-wise genetic distances, no difference was observed between races 4 and 7 of FOV. Results from our research provided for the first time a comprehensive study on the identification of FOV races collected from different regions of Uzbekistan. In addition, this study will help breeders to develop resistance management strategies to combat the Fusarium wilt disease by breeding resistant cotton lines in Uzbekistan.
\end{abstract}

Keywords: FOV, cotton, wilting disease, Fusiarum, race identification

\section{Introduction}

Fusarium wilt of cotton, caused by Fusarium oxysporum Schlect. f. sp. vasinfectum (FOV) (Atk.) Snyd \& Hans., is a serious threat to cotton (Gossypium spp.) in many production regions in the world [1-6]. FOV is a soil-inhabiting fungus that can survive for long periods in the absence of a host, making it impractical to eradicate the fungus from infested fields. Although some progress has been accomplished in managing the disease, host plant resistance remains the most sustainable way to confront Fusarium wilt of cotton [6].

FOV is comprised of different genotypes, sometimes called races. At least eight races (race 1 to race 8 ) and several undesignated genotypes have been described throughout the world $[7,8]$. Races were originally classified based on pathogenicity tests on different cotton species including Gossypium hirsutum L, G. barbadense L. and G. arboreum L. [9-11], and by their pathogenicity on alfalfa (Medicago sativa L.), soybean (Glycine max L.), and tobacco (Nicotiana tabacum L.) $[\mathbf{1 1 , 1 2 ]}$. However, results of pathogenicity tests on hosts other than cotton were difficult to reproduce and were not appropriate for defining races $[1,3,6]$. More recently, FOV genotypes have been defined based on differences in DNA sequences, eg., sequences of the translational elongation factor (EF-1a), the phosphate permase (PHO) and the beta-tubulin (BT) genes, and intergenic spacer (IGS) regions using restriction enzymes $[3,8,13]$. Worldwide, genotypes of FOV can be classified into five major lineages such as race $1,3,4,8$, and Australian race $[3,7,8]$.

In the U.S.A., the FOV disease was first reported in 1892 in Alabama cotton fields [14], and since then it has been reported in all of the major cotton producing regions in the world. It was also reported that the disease is more severe in the presence of the root-knot nematode (RKN), Meloidogyne incognita (Kofoid \& White) Chitwood [14]. In cotton, little is known about the genetic basis for resistance to FOV genotypes, or how these geneotypes are affected by environmental factors and interactions with other pathogens (eg., RKN and reniform nematodes, Verticillium wilt caused by Verticillium dahliae, or black root rot caused by Thielaviopsis basicola) [6]. The postulated pathogenicity mechanisms and the inheritance of FOV resistance significantly differ among FOV genotypes for cotton cultivars $[2,15]$. Phenotypic analyses indicated that resistance to FOV was determined by one or two major genes with complete to incomplete dominance, and possibly additional minor genes $[4,6,16,17]$.

In Uzbekistan, during 1960 to 1970 , cotton production suffered with significant losses in yield and quality because 
Egamberdiev et al. Journal of Plant Science \& Molecular Breeding 2013,

http://www.hoajonline.com/journals/pdf/2050-2389-2-3.pdf

doi: $10.7243 / 2050-2389-2-3$

Table 1. Strains of Fusariuum oxysporium f. sp. vasinfectum of known races and from Uzbekistan collected from symptomatic cotton plants used in the DNA phylogenetic analyses.

\begin{tabular}{|c|c|c|c|c|c|c|}
\hline$\#$ & Isolate & Origin/Year collected & Source/Region isolated & $\begin{array}{l}\text { GenBank } \\
\text { accessions }\end{array}$ & $\begin{array}{l}\text { ID used } \\
\text { in this study }\end{array}$ & $\begin{array}{l}\text { Previously known } \\
\text { race information }\end{array}$ \\
\hline 1 & Race_1_Tulare_CA & USA & R.M. Davis & - & FOV2 & Race 1 (USA) \\
\hline 2 & Race_2_ATCC_16611 & USA & G.M. Armstrong & - & FOV 16611 & Race 2 (USA) \\
\hline 3 & Race_3_Tulare_CA & USA & R.M. Davis & - & FOV3 & Race 3 (USA) \\
\hline 4 & Race_4_Fresno_CA & USA & R.M. Davis & - & FOV 66 & Race 4 (USA) \\
\hline 5 & Race_4_AY714101 & USA & R.M. Davis [3] & AY714101 & & \\
\hline 6 & Race_6_ATCC_36198 & Brazil & G.M. Armstrong & - & FOV36198 & Race 6 (USA) \\
\hline 7 & Race_7_China & China & T. Zhang & - & FOV (China) & Race 7 (China) \\
\hline 8 & Race_7_AF362156 & China & [8] & AF362156 & - & - \\
\hline 9 & Race_8_CA-1_AY714098 & Tulare, CA, USA & S.N. Smith, J.E. DeVay & AY714098 & - & - \\
\hline 10 & LA_110_Group_A & Lousiana, USA & R.M. Davis & - & FOV 110 & Group A (USA) \\
\hline 11 & LA_112_Group_C & Lousiana, USA & R.M. Davis & - & FOV 112 & Group C (USA) \\
\hline 12 & FOV_AUSTRALIA-19_AY714097 & Boggabilla, Australia & S. Bentley [3] & AY714097 & - & \\
\hline 13 & FOV_AUSTRALIA_VCG_1112 & Boggabilla, Australia & R.M. Davis, S. Bentley [3] & - & FOV 19 & Aust VCG 1112 (USA) \\
\hline 14 & FOV_347_UZBEK_Orig (316) & $\mathrm{Uzb} / 2010$ & ${ }^{\star}$ IGPEB/Sirdarya & - & 347 & Unknown \\
\hline 15 & FOV_316_UZBEK_1 & $\mathrm{Uzb} / 2008$ & IGPEB/Tashkent & - & $316(\mathrm{R}-1)$ & Unknown \\
\hline 16 & FOV_316_UZBEK_2 & $\mathrm{Uzb} / 2008$ & IGPEB/Tashkent & - & $316(\mathrm{R}-2)$ & Unknown \\
\hline 17 & FOV_316_UZBEK_3 & $\mathrm{Uzb} / 2008$ & IGPEB/Tashkent & - & $316(\mathrm{R}-3)$ & Unknown \\
\hline 18 & FOV_328_UZBEK_1 & $\mathrm{Uzb} / 2010$ & IGPEB/Bukhara & - & $328(\mathrm{R}-1)$ & Unknown \\
\hline 19 & FOV_444_UZBEK & $\mathrm{Uzb} / 2002$ & IGPEB/Tashkent & - & $444(125)$ & Unknown \\
\hline 20 & FOV_375_UZBEK & $\mathrm{Uzb} / 2001$ & IGPEB/Tashkent & - & $375(120)$ & Unknown \\
\hline 21 & FOV_319_UZBEK & $\mathrm{Uzb} / 2010$ & IGPEB/Namangan & - & $319(\mathrm{R}-1)$ & Unknown \\
\hline
\end{tabular}

* - IGPEB - Institute of Genetics and Plant Experimental Biology collection; Uzb - Uzbekistan. Uzbekistan has 12 province including Andijan, Fergana, Namangan, Tashkent, Sirdayra, Jizzakh, Samarkand, Navoiy, Bukhara, Qashqadaryo, and Surkhondaryo as well as autonomous Republic of Karakalpakstan (listed by closeness to Tashkent).

of Verticillium and Fusarium fungi epidemics, which were efficiently minimized with the development of more resistant Upland cotton varieties [18]. Fusarium genotypes historically affected Pima cottons ( $G$. barbadense), but in the last few years, researchers reported that Upland cultivars (G. hirsutum) have also been affected by Fusarium in different cotton growing regions of Uzbekistan [19]. Since 2002 to present day, the domi-nant reported pathogen causing wilt has been Fusarium, in particular for the long staple Pima-derived upland cotton variety Bukhara-6. Reports from 2007 to 2011 demonstrated that several other Upland cotton varieties also became highly susceptible to Fusarium in Uzbekistan [20].

A unique phytopathogen collection exists in Uzbekistan that was created in 1993 by the initiative of scientists of the Institute of Genetics and Plant Experimental Biology, Academy of Uzbekistan Sciences, within the frame of several governmental and international research projects. The collection includes more than 500 phytopathogen strains belonging to 72 genera and has been recorded and updated through an electronic database [21]. This collection includes many isolates for Fusarium fungi collected from different regions of Uzbekistan without any designation of FOV races. Although previous studies explored a FOV isolate from Uzbekistan and reported that it belonged to race 4 of FOV $[7,22]$, the collected site of the Uzbekistan FOV isolate remained unknown. A comprehensive survey was needed to determine the known distribution of races causing Fusarium wilt in Uzbekistan cotton. Without a proper identification of races, the development of a resistance strategy to breed resistant cultivars for different gene-specificity of FOV races remains elusive. The specific objective of this research was to identify the races of $F$. oxysporum $\mathrm{f}$. sp. vasinfectum isolates collected from cotton plants infected with Fusarium wilt of different geographical regions of Uzbekistan and compare them with a known set of FOV isolates of USA and Australia using candidate genes sequence of some specific genomic regions.

\section{Methods}

\section{Fusarium isolates}

The Fusarium isolates with their origin and source used in this study are presented in Table 1. Briefly, a total of eight samples for Fusarium isolates with unknown race identity from the Republic of Uzbekistan collection were used to isolate genomic DNA for sequencing comparison with known races of FOV (races 1, 2, 3, 4, 6, 7, 8, and Australian VCG1112). Among Uzbekistan samples, isolate no. 316 (with original number 347 ) is widely 
used in many biological experiments, and greenhouse and field evaluations of FOV infection on cultivars and germplasm of Uzbekistan. Isolate no. 316 represented several biological replications (R1, R2 and R3) and was re-isolated from different infected cotton plants under laboratory conditions. For DNA sequence comparisons, 13 genomic DNA samples of known FOV races were used to place the Uzbekistan's isolates into a specific group or FOV race. Known FOV races were provided by researchers and/or DNA sequence was obtained through the NCBI GeneBank (blast.ncbi.nlm.nih.gov) (Table 1).

\section{Isolation of fungal strains}

Infected cotton plants with signs of wilt disease were collected from cotton fields in different regions of Uzbekistan. Diseased plants were washed for 2 hours in tap water and cut on the border of the affected and relatively intact tissues. A piece of cut tissue, after treatment in $0.002 \%$ solution of Tween - 80 for 2 minutes and surface sterilization in $70 \%$ ethanol and $5 \% \mathrm{NaOCl}$ for 30 seconds, was placed on petri dishes with potato dextrose/sucrose/glucose agar supplemented with streptomycin sulfate $0.3 \mathrm{~g}$ per liter and incubated in an environment-control growth chamber (photoperiod 12:00 at $24-25^{\circ} \mathrm{C}$, the period of darkness $12: 00$ at $18^{\circ} \mathrm{C}$ ). Isolation of cultures was carried out by classical methods following Booth [23] and Bilay [24] protocols. Starting from the second day of incubation and during the whole vegetation period, petri dishes with fungi were subjected to microscopy and isolation. Single spore cultures were used for identification of microscopic fungi. Conidia suspension was prepared in the test tubes with a fresh culture of the fungus with a series of consecutive 10-time dilutions. The resulting dilution of conidia was introduced into $2 \%$ agar growth medium and dispensed on sterile petri dishes and incubated at $24-25^{\circ} \mathrm{C}$ for $5-7$ days [24]. Petri dishes only containing single (dense) sporulating colonies were selected for identification of FOV races. Conidial suspension was prepared in sterile water. The concentration of spores was counted under a microscope at low magnification (100-150 $\times)$ and adjusted to a concentration of 10-30 spores in a single drop. On the surface of the agar medium with growth limiter (Triton X-100), a drop of suspension was added to make 10-20 spores. Separately growing colonies were collected 3-5 days later. Confirmation of Fusarium isolates was performed according to Booth [23], and Gerlach \& Nirenberg [25].

\section{Propagation of fungal strains through host plant and pathogenicity test of Fusarium}

Sterile glass tubes were filled with one of the following nutrition medium containing potato dextrose/sucrose/glucose agar slant (PDAS; PGAS; or PSAS) up to $10 \mathrm{~cm}$ scale mark. In 2-3 days fungal strains were placed on to agar surface and incubated in the environmental chamber ( $12 \mathrm{~h}$ of day-light at $24-26^{\circ} \mathrm{C}$ followed by $12 \mathrm{~h}$ in dark at $20-22^{\circ} \mathrm{C}$ ) for 14 days. After incubation the mycelium was covered by warm $\left(45^{\circ} \mathrm{C}\right) \mathrm{Knopp}$ (limited salts) medium up to $3 \mathrm{~cm}$.
Acid delinted and surface sterilized seeds of commercial $G$. hirsutum L. cotton varieties (AN-Boyovutt -2, Namangan - 77, Navbahor, Gulbahor) were placed on Knopp medium. Each tube containing single cotton seed with the fungal strain was placed into a growth chamber for $8-10$ days at $22^{\circ} \mathrm{C}$. After incubation the diseased seedlings were subjected to mycological testing and further re-isolation of fungal strain. For the pathogenicity test, acid delinted and surface sterilized seeds of AN-Bayaut -2, Namangan - 77, Navbahor, Gulbahor cultivars were grown in petri dishes on filter paper in sterile conditions at $22^{\circ} \mathrm{C}$. After germination, only intact and healthy seedlings were used for further pathogenicity testing. Fungal cultures were incubated on potato glucose agar slant (PGAS) petri dishes in the environmental chamber ( $12 \mathrm{~h}$ of day-light at $24-26^{\circ} \mathrm{C}$ followed by $12 \mathrm{~h}$ in dark at $20-22^{\circ} \mathrm{C}$ ) for 14 days. Ready growth mycelium with conidia was washed by 5-7 ml sterile water and was passed through sterile cheesecloth into tubes. The volume of suspension for each strain was brought up to $50 \mathrm{ml}$. The conidia suspension was adjusted to $1 \times 10^{6}$ $\mathrm{con} / \mathrm{ml}$ concentration, calculated by using hemocytometer. Pathogenicity test was performed using seedlings of the above cotton cultivars placed on petri dishes with conidia suspension (a more comprehensive pathogenicity study with these and additional genotypes will be published elsewhere).

\section{DNA isolation and sequencing}

Monospore isolates grown on petri dishes were used for DNA isolation. For each sample $200 \mathrm{mg}$ of mycelium was ground into powder in liquid nitrogen. DNA was extracted following previously published protocol $[23]$ and stored at $-20^{\circ} \mathrm{C}$. Genespecific primers were used to amplify genomic regions on selected FOV isolates (Table 2). Primer combinations used were EF1a/EF2a, BT3/BT5, rDNA 18s/rDNA $28 \mathrm{~S}$ that produced 500-600 bp PCR amplicons. Amplification was carried out in $25-\mu \mathrm{l}$ reactions containing $1.5 \mu \mathrm{l} 10 \mathrm{ng} / \mu \mathrm{l}$ of DNA, $2.5 \mu \mathrm{l}$ of 10 x PCR buffer containing $100 \mathrm{mM}$ Tris- $\mathrm{HCl}, \mathrm{pH} 8.3$ at $25^{\circ} \mathrm{C}, 500$ $\mathrm{mM} \mathrm{KCl}$ and $15 \mathrm{mM} \mathrm{MgCl}{ }_{2}, 0.2 \mu \mathrm{l}$ of $25 \mathrm{mM} / \mu \mathrm{l}$ of dNTPs, $0.5 \mu \mathrm{l}$ of $1 \mathrm{mg} / \mathrm{ml} \mathrm{BSA}, 0.37 \mu \mathrm{l}(5 \mu \mathrm{M})$ of each primer, 1 unit of Taq polymerase (Applied Biosystems, Foster City, CA) and pure (milli-Q) water using a thermocycler (Gene Amp, PCR System 9700), following PCR-conditions and protocols described by previous studies (Table 2). A negative control (no template DNA) was included in each PCR reaction. Amplicons were visualized in $2 \%$ agarose gel by staining with ethidium bromide. The products were purified with polyethylene glycol (PEG) solution (containing 26\% PEG $8000,6.5 \mathrm{mM} \mathrm{MgCl}$ and $0.6 \mathrm{mM}$ sodium acetate $\mathrm{pH} 5.2$ ) to remove remaining primers. The purified PCR-products were then directly sequenced in both directions using 3130xl Genetic Analyzer (Applied Biosystems, Foster City, CA).

\section{Data analysis}

Sequences were analyzed with the Lasergene $V 9.1$ computer program (DNASTAR, Madison, WI, USA). After each DNA 
Egamberdiev et al. Journal of Plant Science \& Molecular Breeding 2013,

http://www.hoajonline.com/journals/pdf/2050-2389-2-3.pdf

doi: $10.7243 / 2050-2389-2-3$

Table 2. Primers used for FOV race identification.

\begin{tabular}{|c|c|c|c|}
\hline Primer name & Forward 5' to 3' & Reverse 5' to 3' & Amplicon size, bp \\
\hline \multicolumn{4}{|c|}{ Ribosomal DNA (rDNA) (1) } \\
\hline $18 \mathrm{~S}$ & TTTCCGTAGGTGAACCTGCGGAAGG & - & 600 \\
\hline $28 \mathrm{~S}$ & - & CGCTTATTGATATGCTTAAACTCA & \\
\hline \multicolumn{4}{|c|}{ Translation elongation factor (EF-1a), (27) } \\
\hline EF-1 & ATGGGTAAGGAAGACAAGAC & - & 600 \\
\hline EF-2 & - & GGAAGTACCAGTGATCATGTT & \\
\hline \multicolumn{4}{|c|}{$\beta$-tubulin (BT), (18) } \\
\hline BT-3 & CGTCTAGAGGTACCCATACCGGCA & - & 500 \\
\hline BT-5 & - & GCTCTAGACTGCTTTCTGGCAGACC & \\
\hline
\end{tabular}

sequence from each selected genotype was proofed and trimmed using the software from the ABI DNA Genetic Analyzer (Applied Biosystems, Foster City, CA), sequence data were imported into the Lasergene V 9.1 computer program (DNASTAR, Madison, WI) for further analysis. EditSeq (DNASTAR, Madison, WI) was used as a sequence editor and import or export tool. Sequence identities were determined using BLAST from the National Center for Biotechnology Information (NCBI) (blast. ncbi.nlm.nih.gov). MegAlign (DNASTAR, Madison, WI) was used to generate pairwise and multiple sequence alignments of DNA and reports and percentage identity tables showing the numerical data underlying the comparisons. The Hein [26] and ClustalW [27] methods were used for aligning all sequences in the work-table. Phylogenetic trees were created using Phylogenetic Analysis Using Parsimony (PAUP) software [28] ver. 4.0 beta with parsimony option selected for analysis. To statistically support the clades 1000-times bootstrapping analysis [29] were performed using the PAUP software. Trees presented are depicted using tree figure drawing tool 'FigTree' ver.1.31. (http://tree.bio.ed.ac.uk/) from output file of PAUP.

\section{Results and discussions}

Fungal strains and host plant infection

Isolates of Fusarium from the Uzbekistan collection included in this study caused at least mild disease symptoms. Inoculated plants or seedlings showed wilt symptoms such as epinasty and slight dwarfing and chlorotic leaves. Brown to black spots were determined across most vascular tissues in root-stem cross section of infected plants. Similar wilt symptoms have been reported in different FOV studies [1,3-6]. The identity of most of all the isolates recovered from inoculated plants from Uzbekistan was confirmed by EF-1a, BT, and rDNA marker-gene sequences as described below.

\section{Phylogenetic analyses}

We collected genomic DNA for most known races of FOV worldwide to identify Fusarium isolates from the Uzbekistan phytopathogen collection. We sequenced fragments of specific marker-genes such as elongation factor (EF-1a), beta-tubulin (BT), and ribosomal DNA (rDNA) using primer-pairs recently used to identify the races of the FOV pathogen (Table 2). DNA sequences were compared to published FOV DNA markergene sequences using BLAST from the NCBI (blast.ncbi.nlm. nih.gov) to confirm similarity to FOV. Except for two unknown Uzbek isolates (FOV_319 and FOV_444), DNA sequences for all gene fragments of remaining samples used in our study (Table 1) were confirmed to belong to Fusarium oxysporum $f$. sp. vasinfectum. BLAST results of EF-1a sequences indicated that isolate FOV_319 and FOV_444 more likely belongs to other Fusarium species (data not shown); therefore, they were removed from further analyses with EF-1a sequences.

Phylogenetic analysis based on individual marker-gene sequence data statistically clustered all FOV samples into distinct groups. Although sequence data from all genes used in our study revealed similar phylogenetic groups and tree topology, herein, we first present our results only using EF-1a marker-gene to explain and view the generated phylogram. We removed the biological replications for some samples (eg., for isolate no 316 or one of the highly similar FOV sequences for Australia isolate) from the final tree (Figure 1). The phylogenetic tree demonstrated that all unknown Fusarium isolates of Uzbekistan clustered into 3 major clades with known races of FOV (Figure 1). FOV strain from Australia (FOV_AUSTRALIA_19_AY714097) and isolate Group C (LA_112_Group_C) were placed as out groups. The first clade included the known race 3 of FOV [10]. One of the unknown Uzbekistan FOV isolate (no. 316) was included with the race $3 \mathrm{FOV}$ clade. The second clade included the known races 4 and 7 of FOV $[3,8]$ with the unknown Uzbekistan FOV isolate no. 328 , which also clustered within the FOV strain Group A (LA_110 Goup A). The third clade included known races 1, 2 \&6 and one of unknown Uzbekistan FOV isolate no. 375. Phylogenetic clades 2 and 3 were closer to each other and rooted from one of the known FOV genotype - race 8 (Table 1 and Figure 1).

These phylogenetic groups based on EF-1a gene sequence can also be clearly demonstrated with pairwise genetic distance shown in Table 3. Out-group FOV samples were distantly related and three major clades share greater genetic similarity within each clade (Table 3 and Figure 1). Even though FOV races 

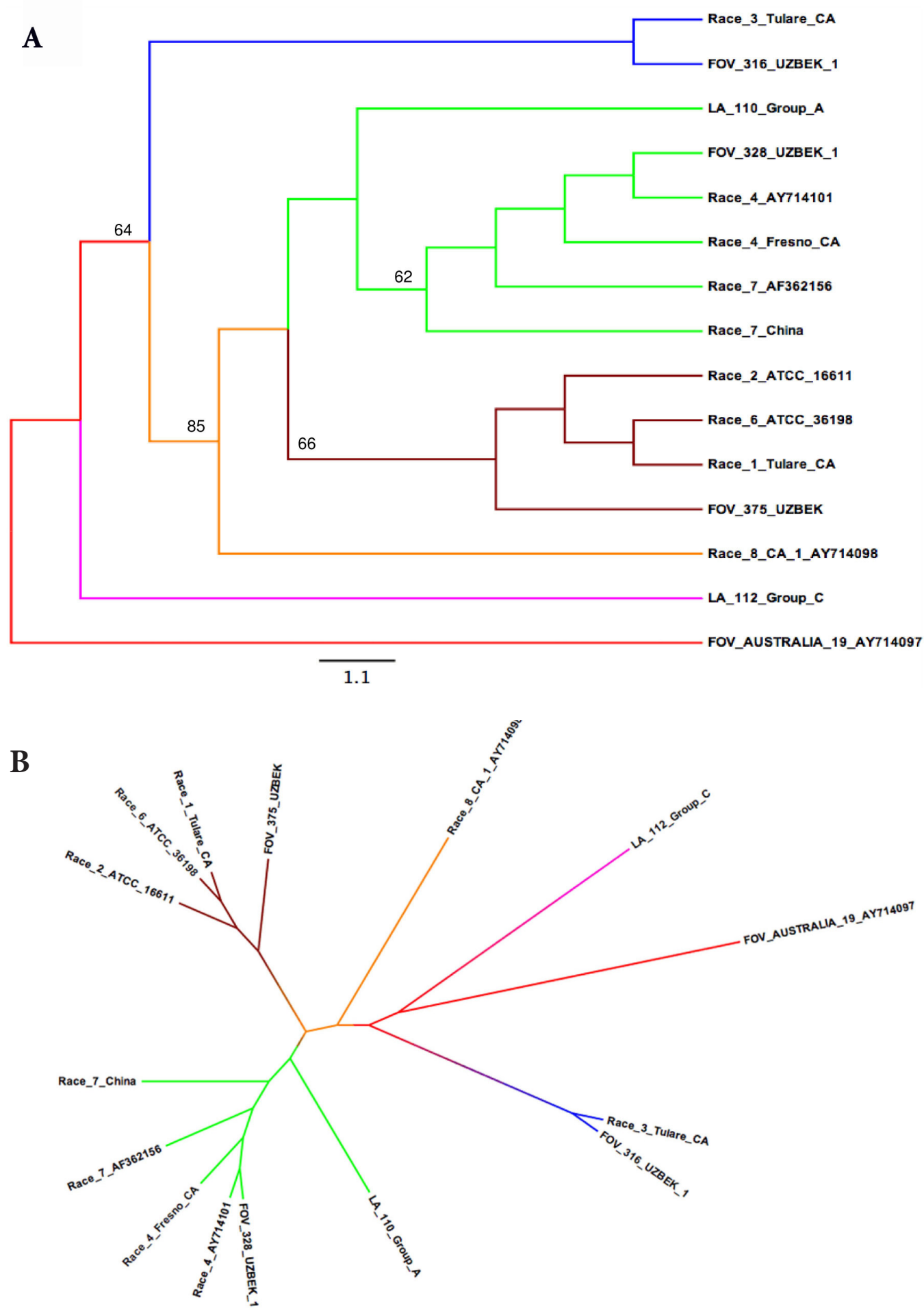

Figure 1. Parsimony based molecular phylogeny of FOV races based on EF-1 1 gene sequences: (A) arbitrary rooted and (B) - unrooted phylogenetic trees. Tree depicted using tree figure drawing tool 'FigTree' ver.1.31. (http://tree.bio.ed.ac.uk/) from output file of PAUP. Branch lengths and bootstrap values from 1000 replications are shown. Clades are color-coded for simplicity: clade 1- blue, clade 2-green, clade 3 - maroon color-coded. 
Egamberdiev et al. Journal of Plant Science \& Molecular Breeding 2013,

http://www.hoajonline.com/journals/pdf/2050-2389-2-3.pdf

doi: $10.7243 / 2050-2389-2-3$

Table 3. Pairwise genetic distance estimates based on Elongation Factor (EF-1a) gene sequence that were generated using MegAlign (DNASTAR).

\begin{tabular}{|c|c|c|c|c|c|c|c|c|c|c|c|c|c|c|c|}
\hline Fusarium Wilt & 1 & 2 & 3 & 4 & 5 & 6 & 7 & 8 & 9 & 10 & 11 & 12 & 13 & 14 & 15 \\
\hline Race_1_Tulare_CA & $* * *$ & 99.8 & 96 & 99.5 & 99.5 & 100 & 99.5 & 98.7 & 97.1 & 97.4 & 99.5 & 99.8 & 99.5 & 99.4 & 96.1 \\
\hline Race_2_ATCC_16611 & 0.2 & $* * *$ & 96.1 & 99.7 & 99.7 & 99.8 & 99.7 & 98.9 & 97.2 & 97.6 & 99.7 & 99.7 & 99.7 & 99.5 & 96.3 \\
\hline Race_3_Tulare_CA & 1.3 & 1.1 & $* * *$ & 96.1 & 96.1 & 96 & 96.1 & 97.1 & 97.9 & 98.5 & 96.1 & 95.8 & 96.1 & 96 & 93.5 \\
\hline Race_4_Fresno_CA & 0.5 & 0.3 & 1.1 & $* * *$ & 100 & 99.5 & 100 & 98.9 & 97.2 & 97.6 & 100 & 99.4 & 100 & 99.5 & 96.1 \\
\hline Race_4_AY714101 & 0.5 & 0.3 & 1.1 & 0 & $* * *$ & 99.5 & 100 & 98.9 & 97.2 & 97.6 & 100 & 99.4 & 100 & 99.5 & 96.1 \\
\hline Race_6_ATCC_36198 & 0 & 0.2 & 1.3 & 0.5 & 0.5 & $* * *$ & 99.5 & 98.7 & 97.1 & 97.4 & 99.5 & 99.8 & 99.5 & 99.4 & 96.1 \\
\hline Race_7_China & 0.5 & 0.3 & 1.1 & 0 & 0 & 0.5 & $* * *$ & 98.9 & 97.2 & 97.6 & 100 & 99.4 & 100 & 99.5 & 96.1 \\
\hline LA_110_Group_A & 0.5 & 0.3 & 1.1 & 0.3 & 0.3 & 0.5 & 0.3 & $* * *$ & 98.1 & 98.4 & 98.9 & 98.5 & 98.9 & 98.7 & 95.3 \\
\hline LA_112_Group_C & 1.3 & 1.1 & 1.3 & 1.1 & 1.1 & 1.3 & 1.1 & 1.1 & $* * *$ & 99 & 97.2 & 96.9 & 97.2 & 97.1 & 94.4 \\
\hline FOV_316_UZBEK_1 & 1 & 0.8 & 0.7 & 0.8 & 0.8 & 1 & 0.8 & 0.8 & 1 & $* * *$ & 97.6 & 97.2 & 97.6 & 97.4 & 94.7 \\
\hline FOV_328_UZBEK_1 & 0.5 & 0.3 & 1.1 & 0 & 0 & 0.5 & 0 & 0.3 & 1.1 & 0.8 & $* * *$ & 99.4 & 100 & 99.5 & 96.1 \\
\hline FOV_375_UZBEK & 0.2 & 0.3 & 1.5 & 0.7 & 0.7 & 0.2 & 0.7 & 0.7 & 1.5 & 1.1 & 0.7 & $* * *$ & 99.4 & 99.2 & 96 \\
\hline Race_7_AF362156 & 0.5 & 0.3 & 1.1 & 0 & 0 & 0.5 & 0 & 0.3 & 1.1 & 0.8 & 0 & 0.7 & $* * *$ & 99.5 & 96.1 \\
\hline Race_8_CA-1_AY7141098 & 0.7 & 0.5 & 1.3 & 0.5 & 0.5 & 0.7 & 0.5 & 0.5 & 1.3 & 1 & 0.5 & 0.8 & 0.5 & $* * *$ & 96.1 \\
\hline FOV_AUSTRALIA-19_AY714097 & 1.8 & 1.6 & 1.8 & 1.6 & 1.6 & 1.8 & 1.6 & 1.6 & 1.8 & 1.5 & 1.6 & 2 & 1.6 & 1.8 & $* * *$ \\
\hline
\end{tabular}

Percent of Similarity in upper triangle.

Percent of Divergence in lower triangle.

can be classified with gene-markers, certain FOV strains still are difficult to classify and place in specific lineages [30]. The phylogenetic results of this study suggest that in the Uzbekistan phytopathogen collection, FOV_375_Uzbek isolate belongs to the races 1, 2, and 6 of FOV group based on a 99.7 genetic distance (GD); FOV_316 Uzbek isolate belongs to race 3 of FOV $(\mathrm{GD}=98.5)$; and FOV_328 Uzbek isolate belongs to the races 4 and 7 group $(G D=100)$. In a previous study [31], races 4 and 7 were indistinguishable genetically using marker-genes EF-1a and rDNA sequence data. However, pathogenicity tests have shown race $7 \mathrm{FOV}$ from China to be different from race $4 \mathrm{FOV}$ of India. Race 4 was more pathogenic to Pima cottons than race 7 , while race 7 was more pathogenic to Upland cottons than race 4 [9]. Additional research is needed to resolve the conflict between pathogenicity tests and genetic relatedness studies for distinguishing races 4 and 7, and/or other conflicts between races.

To get additional confirmation of our FOV race findings, we combined sequence data for all three used genes (EF-1a, BT, and rDNA) in our study and reanalyzed the phylogenetic groupings as shown in Figure 2. Results were highly similar to what we previously observed with the EF-1a gene sequence analysis. However, one unknown FOV isolate from the Uzbekistan collection (FOV_444_Uzbek) grouped within the clade of FOV races $1,2 \& 6$, revealing the race identity of this isolate. However, the other unknown isolate FOV_319_Uzbek remained very distant and was an out group for the tree presented in Figure 2. Based on NCBI blast results, isolate FOV_319_Uzbek might belong to $F$. solani (data not shown). These results showed that a combination of several gene sequences was useful to resolve differences in inter- and intraspecies level.
Similar phylogentic relationships have been reported for the classification of the known races of FOV using EF-1a and BT marker-genes [3,31,32]. For example, races 1 and 6 were reported to be similar with clades bootstrapping numbers of 86 and $65[3,32]$ which were similar to our bootstrapping numbers (Figures 1,2). In addition, race 4 of FOV grouped closer to LA_110_Group_A [32], and in our study, the phylogenetic clade of races 4 and 7 was rooted to the LA_110_Group A FOV strain (Figure 1).

The marker-genes demonstrated a reliability of race identity for unknown FOV isolates from Uzbekistan using a comparative sequencing approach. This is a significant step forward because it allows us to understand FOV disease symptoms and its spread, and to correctly design and judge biological and genetic experiments. The F. oxysporum f. sp. vasinfectum pathogenicity mechanisms and the inheritance of FOV resistance-genes significantly differ among FOV races for cotton genotypes $[6,15]$. In recent inheritance and quantitative trait (QTL) studies $[6,17,33]$, resistance to races 1,7 and the Australian Fov races was reported to be inherited by gene interactions detected in more than one chromosome. Recently, a major dominant gene conferred resistance to race $4 \mathrm{FOV}$ in Pima-S6 $[6,15]$. Collectively the results from these studies suggest a different gene-specificity of FOV resistance in cotton (Fov1 (race 1) - chromosome 16, Fov4 (race 4) - chromosome 14, FW (race 7) - chromosome 17, and - Australian race of Fov - chromosomes 6, 22, and 25) $[6,15,17,33]$.

\section{Conclusions}

In this study, we explored the FOV isolates collected from Uzbekistan farmer's land and identified several FOV races, 


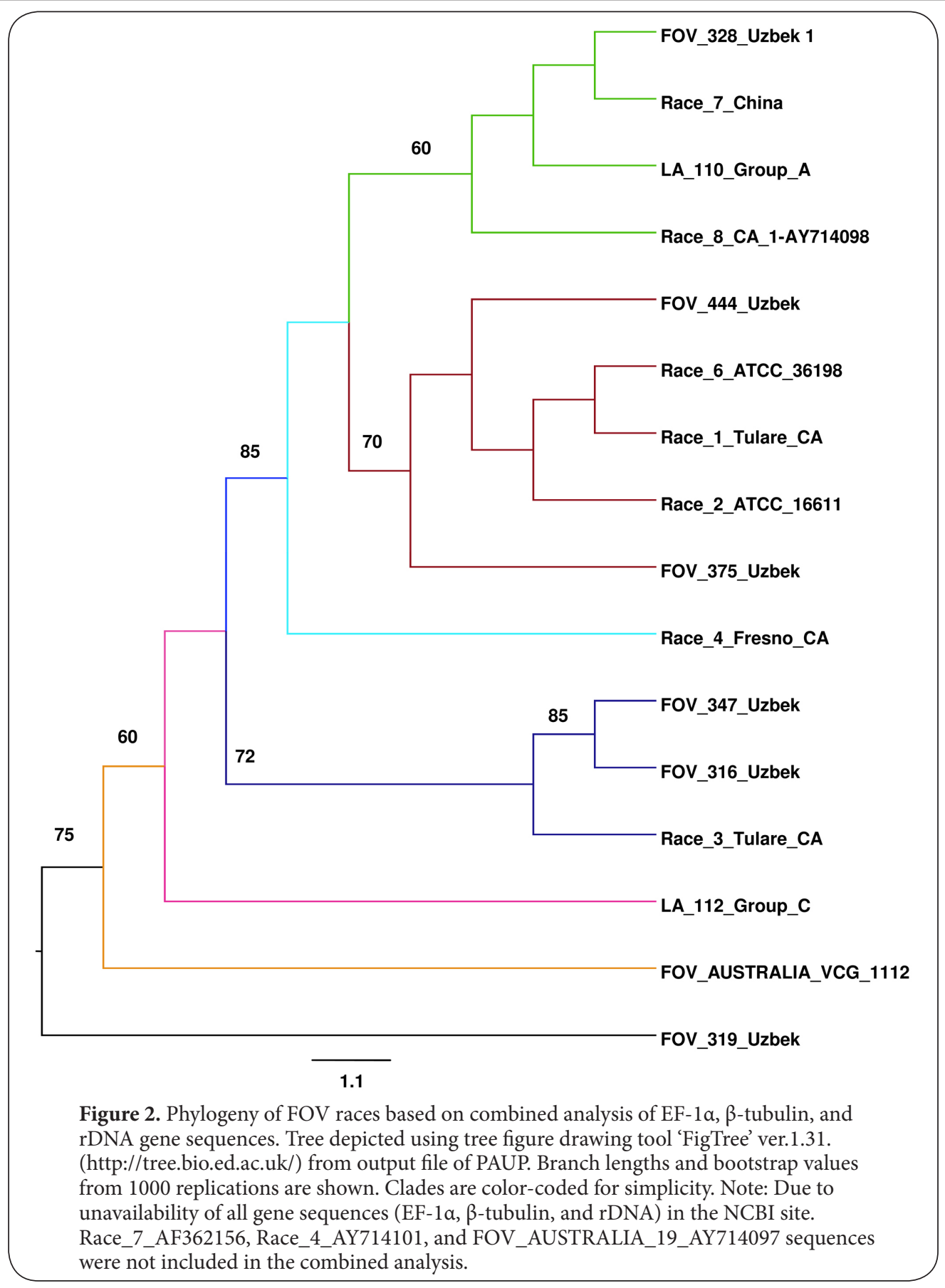

which add knowledge about FOV genotypes spread in Uzbekistan, helping to understand the genetic mechanisms of FOV resistance. Results should be useful for phytosanitary services in Uzbekistan to quickly diagnose and monitor the FOV in Uzbekistan as well as for running an efficient breeding programs to breed the resistant cultivars based on FOV genotypes attacking the cotton.

\section{Competing interests}

The authors declare that they have no competing interests.

\section{Authors' contributions}

SSE, MU, SS, JNJ and IYA designed the experiment, performed data collection and data analysis as well as drafted the manuscript. SSE, IBS, AA, ATA, and BES performed pathogenicity analysis, DNA isolation, sequencing of candidate genes and data analysis. LAG provided FOV isolates from the collection and prepared fungal cultures for the study. MU, SS, JNJ and IYA monitored the experimental work and critically read and edited the manuscript. All authors read and approved the final manuscript.

Acknowledgement and funding The authors thank the Office of International Research Programs, 
US Department of Agriculture (USDA) for funding this study under research grant UZB2-31016-TA-09 and U.S. Civilian Research \& Development Foundation (CRDF) for project coordination. We thank Dr. Tianzen Zhang, National Key laboratory, Nanjing University, China for providing genomics DNAs for FOV race 7 from China. We are indebted to Dr. R. Davis, Department of Plant Pathology, Univ. of CaliforniaDavis, Davis, California, USA for providing reference FOV race DNAs and for his useful comments while reading the draft of the manuscript. Mention of trade names or commercial products in this article is solely for the purpose of providing specific information and does not imply recommendation or endorsement by the U. S. Department of Agriculture.

Publication history

Received: 25-Apr-2013 Revised: 27-May-2013

Accepted: 01-Jun-2013 Published: 11-Jun-2013

\section{References}

1. Kochman J, Swan LL, Moore N, Bentley S, O'Neill W, Mitchell A, Obst N, Lehane J, Gulino L and Salmond G: The Fusarium threat-are we making the progress?. Proceeding of $11^{\text {th }}$ Cotton Conference, Brisbane, Australia $13^{\text {th }}-15^{\text {th }}$ August 2002, 643-652. I Website

2. Wang $B, B$ Bubaker $C L$ and Burdon JJ: Fusarium species and Fusarium wilt pathogens associated with native Gossypium populations in Australia. Mycol Res 2004, 108:35-44. | Article | PubMed

3. Kim Y, Hutmacher RB and Davis RM: Characterization of California Isolates of Fusarium oxysporum f. sp. vasinfectum. Plant Disease 2005, 89(4): 366-372. | Article

4. Ulloa M, Hutmacher RB, Davis RM, Wright SD, Percy R and Marsh B: Breeding for Fusarium wilt Race 4 resistance in cotton under field and greenhouse conditions. J. Cotton Sci. 2006, 10: 114-127. | Article

5. Ulloa M, Percy R, Zhang J, Hutmacher RB, Wright SD, Davis R.M: Registration of four Pima cotton germplasm lines having good levels of Fusarium wilt Race 4 resistance with moderate yields and good fibers. J. Plant Registr. 2009, 3: 198-202. | Article

6. Ulloa M, Wang C, Hutmacher RB, Wright SD, Davis RM, Saski CA and Roberts PA: Mapping Fusarium wilt race 1 resistance genes in cotton by inheritance, QTL and sequencing composition. Mol Genet Genomics 2011, 286:21-36. | Article | PubMed

7. Fernandez D, Assigbese K, Dubois MP and Geiger JP: Molecular characterization of races and vegetative compatibility groups in Fusarium oxysporum f. sp. vasinfectum. Appl Environ Microbiol 1994, 60:4039-46. | Article | PubMed Abstract | PubMed Full Text

8. Skovgaard K, Nirenberg HI, O'Donnell K and Rosendahl S: Evolution of Fusarium oxysporum f. sp. vasinfectum Races Inferred from Multigene Genealogies. Phytopathology 2001, 91:1231-7. | Article I PubMed

9. Armstrong GM and Armstrong JK: American, Egyptian, and Indian cotton-wilt Fusaria: Their pathogenicity and relationship to other wilt Fusaria. U.S. Dep. Agric. Tech. Bull 1960, 219:19. | Pdf

10. Ibrahim FM: A new race of the cotton wilt Fusarium in the Sudan Gezira. Emp. Cotton Grow. Rev 1966, 43: 296-299. I Article

11. Armstrong GM and Armstrong JK: A new race (race 6) of the cotton-wilt Fusarium from Brazil. Plant Dis. Rep. 1978, 62: 421-423. | Article

12. Armstrong GM and Armstrong JK: A race of the cotton wilt Fusarium causing wilt of Yelredo soybean and flue-cured tobacco. Plant Dis. Rep 1958, 42: 147-151.

13. Abd-Elsalam KA, Aly IN, Abdel-Satar MA, Khalil MS and Verreet JA: PCR identification of Fusarium genus based on nuclear ribosomal-DNA sequence data. African Journal of Biotechnology 2003, 2(4): 82-85. | Pdf

14. Atkinson GF: Some diseases of cotton. 3. Frenching. Bull. Ala. Agric. Exp. Stn. 1892, 41: 19-29.

15. Ulloa M, Hutmacher RB, Roberts PA, Wright SD, Nichols RL and Michael Davis R: Inheritance and QTL mapping of Fusarium wilt race 4 resistance in cotton. Theor Appl Genet 2013, 126:1405-18. | Article | PubMed
16. Mohamed HA: Inheritance of Resistance to Fusarium Wilt in some Egyptian Cottons. Empire Cotton Growing Review 1963, 40: 292-295.

17. Wang P, Su L, Qin L, Hu B, Guo W and Zhang T: Identification and molecular mapping of a Fusarium wilt resistant gene in upland cotton. Theor Appl Genet 2009, 119:733-9. | Article I PubMed

18. Marupov A, Kim R, Amanturdiev A, Mirahmedov M, Rahmatov A and Kim $\mathrm{M}$ : Complex of wilt resistance of backcross hybrids of cotton to new virulent isolates of $\boldsymbol{F}$. moniliforme and $\boldsymbol{V}$. dahlie. Republican scientific conference "Achievements of genetics and selection of earliness and resistance traits of agricultural plants to biotic and abiotic factors of enviroment", Tashkent, Uzbekistan 2011 (In Russian).

19. Marupov A, Ishankulova $M$, Rahmatov A and Kim R: About wilt diseases of commercialized cotton varieties. Agrollm 2010, 4(16): 11-13 (in Russian).

20. Marupov A, Boijigitiv F and Irgasheva N: Fusarium wilt of cotton. Agrollm 2012, 2(22):39-40 (in Russian).

21. Gluhova LA, Sheraliev AS, Kryukova OV and Rakhbarova MC: Unique state research facility-Collection of the phytopathogenic microorganisms. Third Congress of Mycology of National Academy of Mycology, Moscow, Russia 2012 (in Russian).

22. Assigbetse KB, Fernandez D, Dubois MP, and Geiger JP: Differentiation of Fusiarum oxysporum $\mathrm{f}$. sp. vasinfectum races on cotton by random amplified polymorphic DNA (RAPD) analysis. Phytopathology 1994, 84:622-626. | Pdf

23. Booth C: Genus Fusarium. Commonwealth Mycological Institute, Kew, Surrey, UK, 1971. | Book

24. Bilay VI: Methods of experimental mycology. Naukova Dumka, Kiev, Ukraine, 1973. (in Russian). I Article

25. Gerlach $\mathrm{W}$ and Nirenberg $\mathrm{HI}$ : The genus Fusarium - a pictorial atlas. Mitt. Biol Bundesanst. Land-u Forstwirsch Berlin-Dahlem 1982, 209: 1-406. | Website

26. Hein J: Unified approach to alignment and phylogenies. Methods Enzymol 1990, 183:626-45. | Article | PubMed

27. Higgins DG and Sharp PM: Fast and sensitive multiple sequence alignments on a microcomputer. Comput Appl Biosci 1989, 5:151-3. | Article | PubMed

28. Swofford DL: PAUP*. Phylogenetic Analysis Using Parsimony (*and Other Methods). Version 4. Sinauer Associates, Sunderland, Massachusetts 2002. I Pdf

29. Felsenstein J: Confidence limits on phylogenies: An approach using the bootstrap. Evolution 1985, 39:783-791. I Pdf

30. Geiser DM, Jimenez-Gasco MM, Kang S, Makalowska I, Veeraraghavan N, Ward TJ, Zhang N, Kuldau GA and O'Donnel K: FUSARIUM-ID v. 1.0: A DNA sequence database for identifying Fusarium. European J. Plant Pathol 2004, 110: 473-479. | Article

31. Shepherd RL: Transgressive segregation for root-knot nematode resistance in cotton. Crop Sci 1974, 14: 872-875. I Article

32. Holmes EA, Bennett RS, Spurgeon DW, Colyer PD and Davis RM: New genotypes of Fusarium oxysporum $\mathrm{f}$. sp. vasinfectum from the southeastern United States. Plant Dis. 2009, 19(12): 1298-1304. | Article

33. Becerra LA, Lopez-Lavalle VJ, Gillespie VJ, Tate WA, Ellis MH, Stiller WN, Lewellyn DL and Wilson IW: Molecular mapping of new sources of Fusarium wilt resistance in tetraploid cotton (Gossypium hirsutum L.). Mol. Breeding 2012, 30: 1181-1191. | Article

Citation:

Egamberdiev SS, Ulloa M, Saha S, Salakhutdinov IB, Abdullaev A, Glukhova LA, Adylova AT, Scheffler $\mathrm{BE}$, Jenkins JN and Abdurakhmonov IY: Molecular Characterization of Uzbekistan Isolates of Fusarium oxysporum f. sp. vasinfectum. Journal of Plant Science and Molecular Breeding 2013, 2:3.

http://dx.doi.org/10.7243/2050-2389-2-3 